\title{
Relações de epífitos vasculares com fatores ambientais nas florestas do Rio Tibagi, Paraná, Brasil
}

\author{
Annete Bonnet ${ }^{1 *}$ \\ Gustavo Ribas Curcio ${ }^{2}$ \\ Osmir José Lavoranti² \\ Franklin Galvão ${ }^{3}$ \\ ${ }^{1} \mathrm{PPG}$ em Ciências Florestais, Universidade Federal do Paraná \\ Avenida Prefeito Lothário Meissner, 632, CEP 80210-170, Curitiba - PR, Brasil \\ ${ }^{2}$ Embrapa Florestas, Colombo - PR, Brasil \\ ${ }^{3}$ Departamento de Ciências Florestais, Universidade Federal do Paraná \\ *Autor para correspondência \\ a_bonnet@hotmail.com
}

Submetido em 27/07/2009

Aceito para publicação em 12/04/2010

\section{Resumo}

O objetivo deste trabalho foi avaliar a relação entre a riqueza de epífitos vasculares e fatores climáticos, geomorfológicos, pedológicos e estruturais da floresta, que se modificam ao longo do rio Tibagi. O grau de substituição das 188 espécies registradas foi elevado, indicando a singularidade das comunidades e sua importância para conservação dos epífitos na bacia do citado rio. A similaridade foi maior entre as áreas mais próximas geograficamente, que possibilitou a formação de três grupos de comunidades epifíticas distribuídas ao longo do rio. A maior riqueza de epífitos foi registrada na região do médio Tibagi, onde as unidades fitogeográficas estão em contato e as florestas apresentam o melhor estado de conservação. O aumento da riqueza epifítica mostrou-se relacionado significativamente apenas com o diâmetro máximo das árvores, fator ambiental importante na ampliação da diversidade alfa. A diversidade beta é, provavelmente, resultado da heterogeneidade ambiental que se expressa, principalmente, por distintos padrões geomorfológicos e condições climáticas entre as áreas de estudo e entre regiões ambientalmente diferentes do rio.

Unitermos: diversidade, ecótono, estrutura da floresta, gradiente

\section{Abstract}

Relationships of vascular epiphytes with environmental factors along the Tibagi River forests, Paraná, Brazil. The aim of this work was to evaluate the relationships of vascular epiphyte richness with climatic, geomorphologic, pedologic and forest structural factors, that change along the Tibagi River. The floristic turnover of the 188 registered species was high, indicating the singularity and importance of the communities to the conservation of epiphytes in the river basin. The similarity was greater between geographically closer areas, which made possible the creation of three groups of epiphytic communities distributed along the river. The greatest richness of epiphytes was registered in the medium Tibagi, where the phytogeographic units are in liaison and the forests present the best conservation status. The increase of epiphytic richness is only significantly and positively related to the maximal diameter of trees, an important environmental factor of the enlargement 
of alpha diversity. The beta diversity results, probably, from environmental heterogeneity which is principally represented by distinctive geomorphologic patterns and climatic conditions between study areas and different environmental regions of the river.

Key words: diversity, ecotone, forest structure, gradient

\section{Introdução}

Como plantas que vivem sobre outras plantas, utilizando-as como suporte, os epífitos necessitam de uma conjunção favorável de fatores ambientais para a sua sobrevivência. A distinção na riqueza de epífitos entre as macrorregiões geográficas deve-se, principalmente, à umidade atmosférica; em hábitats mais secos há diminuição no número de espécies e de indivíduos epifíticos, concentrando sua distribuição nas florestas úmidas tropicais do globo (Gentry e Dodson, 1987).

Estudos com epífitos vasculares no Sul e Sudeste do Brasil demonstram gradientes de diminuição de espécies de leste para oeste (Reitz, 1983; Breier, 2005; Bonnet, 2006; Kersten, 2006) e de norte para sul do país (Reitz, 1983; Waechter, 1992), definidos, principalmente, pela disponibilidade hídrica nos ambientes. Esta é representada pela precipitação média anual, uniformidade da distribuição da precipitação ao longo do ano, quantidade de neblina e umidade relativa do ar. Baixas temperaturas também limitam o crescimento e a sobrevivência dos epífitos (Waechter, 1992), sendo ainda mais graves quando acompanhadas pelo estresse provocado pela seca (Zotz e Hietz, 2001).

Outros fatores também exercem influência na distribuição e riqueza de epífitos em grandes paisagens e nos ambientes que as compõem, como dimensões dos forófitos e sua velocidade de crescimento (Yeaton e Gladstone, 1982; Bonnet et al., 2007), além da idade e qualidade do substrato (Benzing, 1995).

Em ambientes fluviais, mais especificamente, padrões geomorfológicos e pedológicos são fatores que influenciam na riqueza, estrutura e distribuição da comunidade epifítica (Bonnet, 2006; Kersten e Kuniyoshi, 2009). A largura da planície e do rio, o tempo de formação das margens e presença de solos com elevada hidromorfia estão relacionados com a riqueza de bromeliáceas (Bonnet, 2006). Devido à presença do rio, combinações variadas de umidade e de luminosidade aumentam a riqueza e a diversidade de bromeliáceas que colonizam os forófitos mais próximos ao canal (Benzing, 1995; Bonnet, 2006).

$\mathrm{O}$ rio Tibagi, devido à influência da tectônica do arco de Ponta Grossa, possui paisagens muito distintas ao longo do seu curso. Ocorrem mudanças nos padrões de leito do rio e nas feições geomórficas formadoras das margens; alternam-se planícies muito largas e diversos segmentos meândricos com cânions, vales estreitos, cachoeiras e encostas com afloramentos rochosos. Essas paisagens singulares, associadas a diferentes tipos climáticos e vegetacionais, propiciam a existência de hábitats diversos para os epífitos vasculares. Em ambientes fluviais, especificamente, o componente epifítico foi abordado por estudos no estado de São Paulo (Araújo et al., 2004); do Paraná (Silva et al., 1997; Dittrich et al., 1999; Bonnet, 2006; Kersten e Kuniyoshi, 2009) e do Rio Grande do Sul (Rogalski e Zanin, 2003; Giongo e Waechter, 2004).

Considerando a importância da sinúsia epifítica nas florestas tropicais e subtropicais, inclusive em ambientes fluviais, este trabalho teve como objetivos o levantamento de espécies e a análise da relação dos epífitos vasculares com distintos fatores ambientais que se modificam ao longo do rio Tibagi, desde a sua nascente até próximo à sua foz. É esperado que diferentes fatores climáticos, geomorfológicos, pedológicos ou estruturais da floresta interfiram positivamente na riqueza de epífitos.

\section{Material e Métodos}

\section{Áreas de estudo}

O rio Tibagi possui cerca de $530 \mathrm{~km}$ de extensão (Maack, 2002) e percorre o estado do Paraná no sentido sul - norte, sendo o principal afluente do rio 
Paranapanema. O estudo foi realizado, ao longo do citado rio, no período de 2006-2008, desde as suas nascentes, no município de Ponta Grossa (PR), até próximo a sua foz, na região de Londrina (PR), entre as coordenadas geográficas $23^{\circ} 18^{\prime}-26^{\circ} 17^{\prime} \mathrm{S}$ e $49^{\circ} 59^{\prime}-50^{\circ} 58^{\prime} \mathrm{W}$. Para levantamento florístico e análise das variáveis ambientais, foram estabelecidas 23 áreas de estudo, de montante para jusante do rio (Figura 1), segundo cotas altimétricas, características geomorfológicas, climáticas, pedológicas e vegetacionais.

As nove primeiras áreas de estudo (1-9), de montante para jusante do rio (Figura 1), estão inseridas na região de predomínio do tipo climático $\mathrm{Cfb}$, com verões frescos, invernos rigorosos, ocorrência frequente de geadas e sem estação seca definida (IAPAR, 2008). De acordo com uma série de 31 anos de dados climáticos (1974-2004), a temperatura média do mês mais frio nessa região foi $10,9^{\circ} \mathrm{C}$ e do mês mais quente $23,2^{\circ} \mathrm{C}$. No mesmo período, a precipitação média anual registrada foi $1.609 \mathrm{~mm} / \mathrm{ano}$, distribuída em, no mínimo, 104 dias de chuva (Estação de Ponta Grossa). Estas áreas estão inseridas no domínio dos Campos Gerais do Paraná, onde as Estepes são marcadamente intercaladas por capões de floresta com araucária (Floresta Ombrófila Mista) (Maack, 2002).

Em direção à jusante do rio (Figura 1), as oito áreas de estudo seguintes (10-17) pertencem à região de transição entre os tipos climáticos Cfb e Cfa (IAPAR, 2008), que se sucedem ao longo do curso do rio. Nessa região, a precipitação média anual foi $1.602 \mathrm{~mm} /$ ano, distribuída em, no mínimo, 115 dias de chuva; a temperatura média do mês mais frio foi $10,9^{\circ} \mathrm{C}$ e do mês mais quente de $24^{\circ} \mathrm{C}$ (Estação de Telêmaco Borba). A vegetação deste trecho pode ser caracterizada como ecotonal, representada pela transição entre a Floresta Ombrófila Mista e de espécies típicas da Floresta Estacional Semidecidual (FES), além dos fragmentos de Savana (cerrado) registrados na região.

Finalmente, o terceiro segmento do rio (Figura 1), que abrange as seis áreas restantes em direção à foz (18-23), está inserido em clima enquadrado como Cfa, subtropical, com temperatura média do mês mais frio de $15,4^{\circ} \mathrm{C}$ e do mês mais quente $27,1^{\circ} \mathrm{C}$, verões quentes e geadas pouco frequentes. Nesta região existe uma

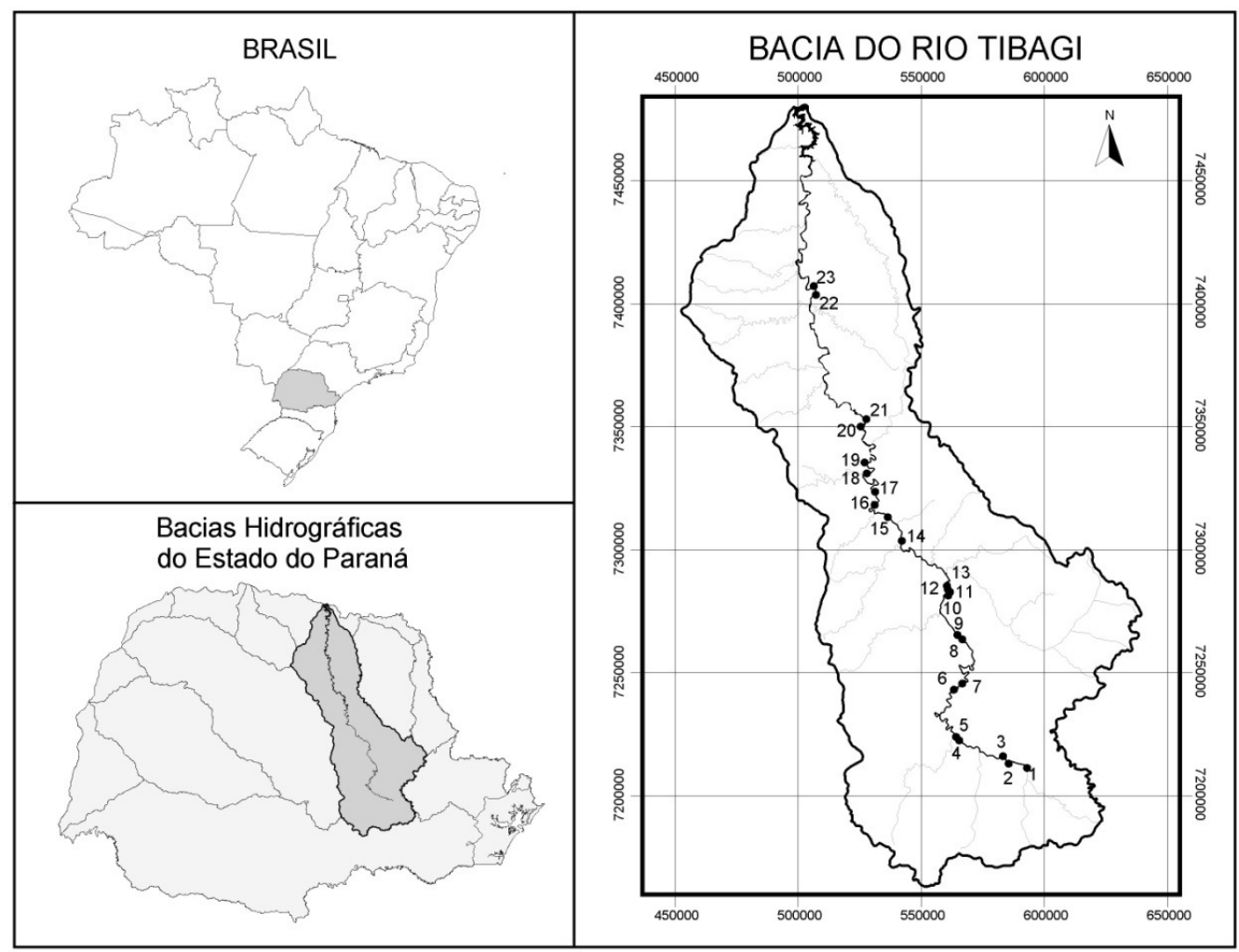

FIGURA 1: Localização das áreas de estudo (áreas 1-23) ao longo do rio Tibagi, Paraná. 
tendência de concentração das chuvas no verão, contudo sem estação seca definida. A precipitação média anual é de $1.531 \mathrm{~mm} / \mathrm{ano}$, distribuída em, no mínimo, 94 dias de chuva (Estação de Ibiporã). A vegetação está sob domínio da Floresta Estacional Semidecidual (FES).

Ao longo de todo o rio Tibagi, é evidente a intervenção antrópica nas florestas por diversas ações e intensidades. Nas áreas com planícies mais extensas, como aquelas próximas ao município de Ponta Grossa, a degradação da vegetação é maior, o que propiciou o intenso desenvolvimento de Guadua aff. paraguayana Döll, taquara nativa extremamente agressiva e oportunista (Galvão et al., 2009). Nas áreas de acesso mais difícil, como próximas da cabeceira do rio, além daquelas preservadas por empresa privada, especificamente no município de Telêmaco Borba, as florestas apresentam o melhor estado de conservação.

\section{Procedimento amostral}

O estudo florístico dos epífitos vasculares foi realizado nas 23 áreas de estudo (Figura 1), através do método do caminhamento (Filgueiras et al., 1994), incluindo somente paisagens caracterizadas, através de geomorfologia e solos, como pertencentes ao ambiente fluvial. O deslocamento abrangeu, em média, dois hectares em cada área, totalizando, aproximadamente, 46ha. Em campo, quando necessário, a visualização e identificação dos epífitos foi realizada com binóculo (7 x 35), utilização de técnicas de escalada simples ou com equipamentos adaptados de montanhismo. Indivíduos estéreis, principalmente da família Orchidaceae, foram coletados para cultivo e posterior identificação.

A identificação das espécies foi baseada em literatura, no estudo de material herborizado e com auxílio de especialistas. Os nomes científicos foram verificados em The International Plant Names Index (IPNI, 2009). As exsicatas foram depositadas no herbário do Departamento de Botânica (UPCB) da Universidade Federal do Paraná.

Os fatores ambientais foram estimados em diferentes escalas da paisagem e integram dados climáticos, geomorfológicos e pedológicos, além de características da floresta e dos indivíduos arbóreos.
$\mathrm{Na}$ escala que abrange toda a extensão do rio (Figura 1), foram registrados dados climáticos, obtidos a partir de uma série de 31 anos das estações anteriormente citadas. As variáveis climáticas foram representadas pelo número mínimo dias chuva/ano (Dmin), menor umidade média mensal (Umin), menor precipitação média mensal (Pmin), menor temperatura média mensal (Tmin) e precipitação total (PrT).

$\mathrm{Na}$ escala das áreas de estudo foram avaliados dados geomorfológicos, como largura máxima da planície e do rio, com apoio de fotografias aéreas, escala 1:25.000, ano de 1980 e mapas planialtimétricos do IBGE, escalas 1:50.000 e 1:100.000. Foi calculada, para cada área de estudo, a razão entre a largura máxima da planície e a largura máxima do rio. Em campo, foi anotada a presença de corredeiras e/ou cachoeiras nas proximidades da área de estudo $(\mathrm{Ch})$, assim como as altitudes (Al), registradas com GPS (Garmin 76CSx) e corrigidas com base nas cartas planialtimétricas. Também foram levantadas características pedológicas, como a presença de solos hidromórficos, baseando-se em características morfológicas.

Em cada área de estudo, foram instaladas doze parcelas com 5 x 10m para levantamento fitossociológico do componente arbóreo. O critério de inclusão das árvores foi apresentar perímetro à altura do peito (PAP) igual ou superior a $15,0 \mathrm{~cm}$, sendo anotados a espécie, altura total e calculados os diâmetros dos indivíduos. As características dos indivíduos arbóreos incluídos na análise estatística foram altura e diâmetro máximos registrados em cada área de estudo, assim como o número de espécies arbóreas (Sarv) e a densidade absoluta total (DAt). Apenas as variáveis estimadas em 19 áreas, dentre as 23 iniciais, foram consideradas na análise das relações entre riqueza de epífitos e fatores ambientais, pois em quatro áreas o tamanho reduzido das florestas impediu o procedimento.

\section{Análise dos dados}

A similaridade entre as comunidades de epífitos registradas nas 23 áreas de estudo distribuídas ao longo do rio foi calculada através do índice de Jaccard e seus resultados utilizados para confeccionar o algoritmo de 
agrupamentos, elaborado com base na metodologia hierárquica-aglomerativa das médias das distâncias. A partir das riquezas de todas as áreas (1-23) foi calculada a diversidade intercomunitária ou beta (Bt), de Wilson \& Shmida (Magurran, 1988), que estima o grau de substituição específica entre as áreas de estudo.

Para verificar o efeito dos fatores ambientais sobre a riqueza de epífitos, foi empregada a análise de regressão múltipla (Draper e Smith, 1981), que evidenciou quais variáveis apresentaram relação significativa com a riqueza de epífitos levantada. Cada uma das 19 áreas de estudo foi considerada uma unidade amostral, organizando-se as informações ambientais de modo semelhante ao apresentado na Tabela 2. Os dados foram analisados utilizando-se o Sistema $\mathrm{SAS}^{\circledR}$, sendo as variáveis ambientais previamente padronizadas conforme a fórmula de ajuste de extensão. Em uma primeira análise, o programa identificou que as variáveis número mínimo de dias de chuva/ano e menor umidade média mensal se mostraram combinações lineares de outras variáveis e, por isso, foram excluídas da análise final de regressão múltipla, cujos resultados são apresentados no texto.

\section{Resultados}

Foram registradas, ao longo do rio Tibagi, 188 espécies de epífitos vasculares, distribuídas em 24 famílias e 86 gêneros (Tabela 1). Destas, 10 famílias, 20 gêneros e 47 espécies são pteridófitas e 14 famílias, 66 gêneros e 141 espécies pertencem às angiospermas. As famílias com maior número de representantes são Orchidaceae ( $40 \%$ do total de espécies), Polypodiaceae (12\%) e Bromeliaceae (12\%).

$\mathrm{O}$ índice de diversidade beta, correspondente ao gradiente florístico existente entre as áreas de estudo instaladas do alto até o baixo rio Tibagi, resultou em $\mathrm{Bt}=4,34$.

As distâncias entre as comunidades epifíticas estão expressas no dendrograma de similaridade, confeccionado com base nos índices de Jaccard (Figura 2). Ao longo do rio Tibagi, a flora epifítica mostrouse mais similar entre as áreas de estudo com maior proximidade geográfica, formando-se, de montante para jusante, três grupos (I, II e III) e sete subgrupos $(\mathrm{a}-\mathrm{g})$ de comunidades epifíticas que mais se assemelham.

TABELA 1: Número de gêneros e espécies de epífitos vasculares registrados ao longo do rio Tibagi, Paraná.

\begin{tabular}{|c|c|c|}
\hline Famílias & Gêneros & Espécies \\
\hline Orchidaceae & 43 & 75 \\
\hline Polypodiaceae & 8 & 23 \\
\hline Bromeliaceae & 7 & 22 \\
\hline Piperaceae & 1 & 15 \\
\hline Cactaceae & 5 & 11 \\
\hline Aspleniaceae & 1 & 5 \\
\hline Commelinaceae & 1 & 5 \\
\hline Hymenophyllaceae & 2 & 4 \\
\hline Selaginellaceae & 1 & 4 \\
\hline Lomariopsidaceae & 1 & 3 \\
\hline Araceae & 1 & 2 \\
\hline Begoniaceae & 1 & 2 \\
\hline Blechnaceae & 1 & 2 \\
\hline Melastomataceae & 1 & 2 \\
\hline Moraceae & 1 & 2 \\
\hline Pteridaceae & 3 & 3 \\
\hline Balsaminaceae & 1 & 1 \\
\hline Dryopteridaceae & 1 & 1 \\
\hline Gesneriaceae & 1 & 1 \\
\hline Myrsinaceae & 1 & 1 \\
\hline Monimiaceae & 1 & 1 \\
\hline Myrtaceae & 1 & 1 \\
\hline Schizaeaceae & 1 & 1 \\
\hline Thelypteridaceae & 1 & 1 \\
\hline Total & 86 & 188 \\
\hline
\end{tabular}

O grupo I reúne comunidades de áreas $(1-9)$ que se concentram no curso superior ou alto Tibagi (Figura 2), e é formado por subgrupos $(a-c)$ que foram registrados no segmento da cabeceira (Figura 2a), no segmento com padrão de leito meandrante livre (Figura 2b) e no padrão meandrante encaixado (Figura 2c). As florestas apresentam, de modo geral, baixa riqueza de espécies epifíticas, sendo estruturadas por árvores em elevadas densidades, com baixos diâmetros e alturas e pertencentes a poucas espécies (Tabela 2). 


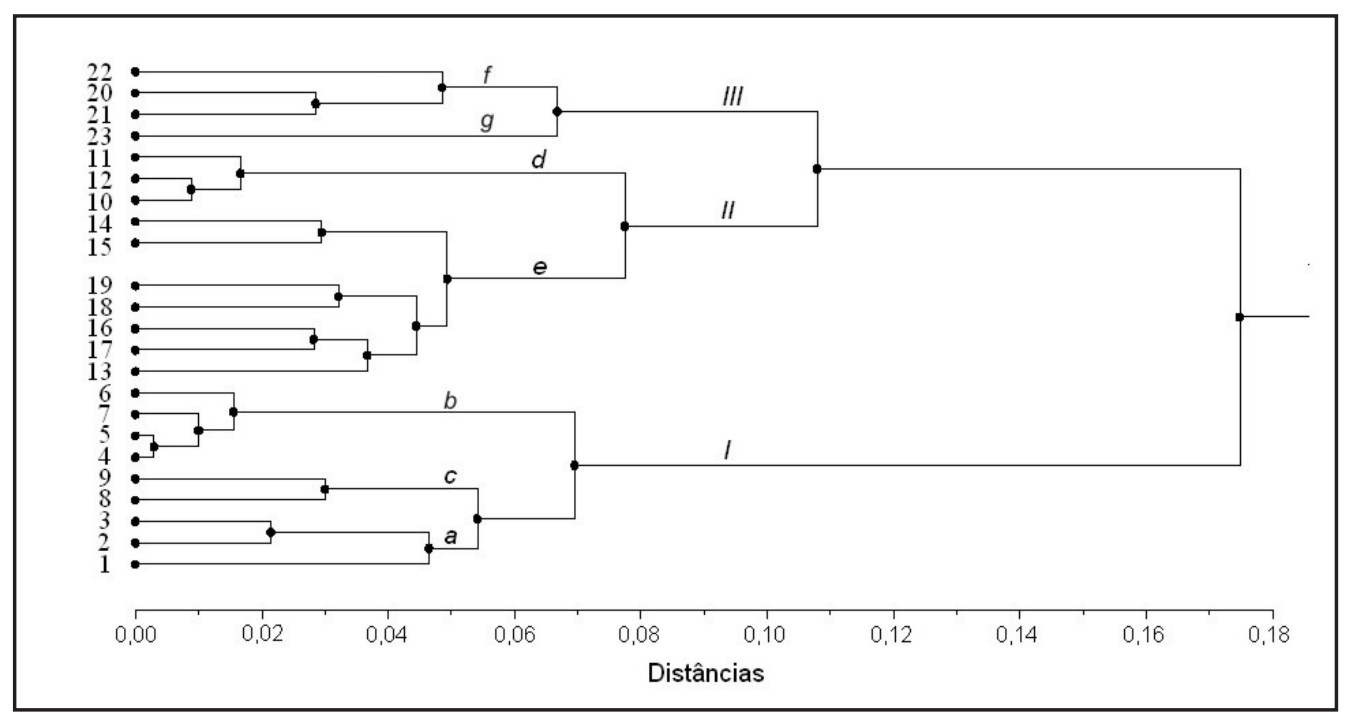

FIGURA 2: Dendrograma das áreas de estudo ao longo do rio Tibagi, baseado na similaridade dos epífitos vasculares. I = grupo do alto Tibagi; II = grupo do médio Tibagi; III = grupo do baixo Tibagi; $\mathrm{a}$ - g = subgrupos de comunidades epifíticas descritas no texto.

TABELA 2: Áreas de estudo e os respectivos fatores ambientais analisados ao longo do rio Tibagi, Paraná.

\begin{tabular}{|c|c|c|c|c|c|c|c|c|c|c|c|c|c|c|c|c|c|}
\hline Áreas & Alt & Cl & UV & Sar & DAP & H & DA & PO & PL & Cach & Hidr & Dmin & Umin & Pmin & Tmin & $\operatorname{Pr} T$ & Sep \\
\hline 1 & \begin{tabular}{|l|}
1100 \\
\end{tabular} & $\mathrm{Cfb}$ & FOM & 24 & 30 & 12 & 2450 & 1 & En & 0 & 1 & 104 & 63 & 1,4 & 10,9 & 1609 & 29 \\
\hline 2 & 940 & $\mathrm{Cfb}$ & FOM & 28 & 89 & 17 & 2483 & 1 & En & 0 & 1 & 104 & 63 & 1,4 & 10,9 & 1609 & 44 \\
\hline 3 & 930 & $\mathrm{Cfb}$ & FOM & 15 & 28 & 10 & 350 & 1 & En & 1 & 1 & 104 & 63 & 1,4 & 10,9 & 1609 & 30 \\
\hline 4 & 780 & $\mathrm{Cfb}$ & FOM & 13 & 36 & 9,5 & 2916 & 0,04 & M1 & 0 & 1 & 104 & 63 & 1,4 & 10,9 & 1609 & 25 \\
\hline 5 & 780 & $\mathrm{Cfb}$ & FOM & 12 & 35 & 10 & 2566 & 0,04 & Ml & 0 & 1 & 104 & 63 & 1,4 & 10,9 & 1609 & 22 \\
\hline 6 & 775 & $\mathrm{Cfb}$ & FOM & 16 & 36 & 11 & 2250 & 0,05 & Ml & 0 & 1 & 104 & 63 & 1,4 & 10,9 & 1609 & 14 \\
\hline 7 & 775 & $\mathrm{Cfb}$ & FOM & 8 & 40 & 11 & 3233 & 0,05 & M1 & 0 & 1 & 104 & 63 & 1,4 & 10,9 & 1609 & 21 \\
\hline 8 & 770 & $\mathrm{Cfb}$ & FOM & 18 & 77 & 14 & 1716 & 0,12 & $\mathrm{Me}$ & 0 & 1 & 104 & 63 & 1,4 & 10,9 & 1609 & 34 \\
\hline 9 & 770 & $\mathrm{Cfb}$ & FOM & 25 & 60 & 18 & 2150 & 0,12 & $\mathrm{Me}$ & 0 & 0 & 104 & 63 & 1,4 & 10,9 & 1609 & 20 \\
\hline 10 & 720 & $\mathrm{Cfb} / \mathrm{Cfa}$ & Ecótono & 36 & 51 & 18 & 1800 & 0,61 & $\mathrm{Me}$ & 0 & 0 & 115 & 64 & 0 & 10,9 & 1602 & 50 \\
\hline 11 & 712 & $\mathrm{Cfb} / \mathrm{Cfa}$ & Ecótono & 24 & 45 & 12 & 1400 & 0,61 & $\mathrm{Me}$ & 1 & 0 & 115 & 64 & 0 & 10,9 & 1602 & 37 \\
\hline 12 & 712 & $\mathrm{Cfb} / \mathrm{Cfa}$ & Ecótono & 33 & 67 & 17 & 2333 & 0,61 & $\mathrm{Me}$ & 1 & 0 & 115 & 64 & 0 & 10,9 & 1602 & 55 \\
\hline 13 & 700 & $\mathrm{Cfb} / \mathrm{Cfa}$ & Ecótono & - & - & - & - & - & - & 1 & 1 & 115 & 64 & 0 & 10,9 & 1602 & 29 \\
\hline 14 & 670 & $\mathrm{Cfb} / \mathrm{Cfa}$ & Ecótono & 39 & 117 & 28 & 1883 & 1 & $\mathrm{Me}$ & 1 & 0 & 115 & 64 & 0 & 10,9 & 1602 & 58 \\
\hline 15 & 630 & $\mathrm{Cfb} / \mathrm{Cfa}$ & Ecótono & 29 & 76 & 28 & 1316 & 1 & $\mathrm{Me}$ & 1 & 0 & 115 & 64 & 0 & 10,9 & 1602 & 56 \\
\hline 16 & 580 & $\mathrm{Cfb} / \mathrm{Cfa}$ & Ecótono & 30 & 51 & 27 & 1566 & 1 & $\mathrm{Me}$ & 1 & 0 & 115 & 64 & 0 & 10,9 & 1602 & 34 \\
\hline 17 & 580 & $\mathrm{Cfb} / \mathrm{Cfa}$ & Ecótono & - & - & - & - & - & - & 1 & 0 & 115 & 64 & 0 & 10,9 & 1602 & 44 \\
\hline 18 & 550 & $\mathrm{Cfb} / \mathrm{Cfa}$ & Ecótono & - & - & - & - & - & - & 1 & 0 & 94 & 47 & 0 & 15,4 & 1531 & 57 \\
\hline 19 & 520 & $\mathrm{Cfb} / \mathrm{Cfa}$ & Ecótono & 36 & 91 & 35 & 1650 & 1 & $\mathrm{Me}$ & 1 & 0 & 94 & 47 & 0 & 15,4 & 1531 & 49 \\
\hline 20 & 430 & $\mathrm{Cfa}$ & \begin{tabular}{|l|} 
FES \\
\end{tabular} & 36 & 60 & 26 & 1916 & 1 & $\mathrm{Me}$ & 1 & 0 & 94 & 47 & 0 & 15,4 & 1531 & 32 \\
\hline 21 & 430 & $\mathrm{Cfa}$ & FES & 35 & 96 & 29 & 1483 & 1 & $\mathrm{Me}$ & 1 & 0 & 94 & 47 & 0 & 15,4 & 1531 & 30 \\
\hline 22 & 340 & $\mathrm{Cfa}$ & FES & 34 & 65 & 17 & 1566 & 0,92 & $\mathrm{Me}$ & 1 & 0 & 94 & 47 & 0 & 15,4 & 1531 & 39 \\
\hline 23 & 340 & $\mathrm{Cfa}$ & FES & - & - & - & - & - & - & 1 & 1 & 94 & 47 & 0 & 15,4 & 1531 & 7 \\
\hline
\end{tabular}

Alt $=$ altitude $; \mathrm{Cl}=$ tipo climático; $\mathrm{UV}=$ unidade vegetacional; $\mathrm{Sar}=\mathrm{n}^{\circ}$ de espécies de árvores; $\mathrm{DAP}=$ diâmetro máximo altura do peito; $\mathrm{H}=$ altura total máxima; $\mathrm{DA}=$ densidade absoluta total das árvores; $\mathrm{PO}=$ razão largura máxima da planície e do rio; $\mathrm{PL}=$ padrão leito do rio; $\mathrm{Cach}=$ presença cachoeiras; $\mathrm{Hidr}=$ presença solos hidromórficos; $\mathrm{Dmin}=\mathrm{n}^{\mathrm{0}}$ mínimo de dias de chuva/ano; Umin $=$ menor umidade média mensal; Pmin = menor precipitação média mensal; $\operatorname{Tmin}=$ menor temperatura média mensal; $\operatorname{PrT}=$ precipitação total; Sep $=\mathrm{n}^{\mathrm{o}}$ total de espécies epifíticas. 
O grupo II corresponde às comunidades registradas nas áreas do médio rio Tibagi $(10-19)$, e é formado por dois subgrupos $(\mathrm{d}-\mathrm{e})$ : das comunidades epifíticas localizadas em ambientes de planícies estreitas (Figura 2d) e, mais a jusante do rio, das comunidades de florestas estabelecidas nas margens do rio completamente encaixado e sem planícies (Figura 2e). Estas comunidades apresentam as maiores riquezas epifíticas registradas ao longo do rio Tibagi (Tabela 2). Nas florestas destacase, predominantemente, o elevado número de espécies de árvores, representadas por indivíduos com altos diâmetros e alturas.

Finalmente, o grupo III reúne as comunidades de epífitos registradas nas áreas (20-23) do baixo rio Tibagi, (Figura 2), sendo formado por dois subgrupos de epífitos ( $f-g$ ) existentes em florestas estabelecidas em vale profundamente entalhado e em vale bem aberto (Figura 2f) e nas ilhas fluviais (Figura 2g). As riquezas epifíticas registradas são intermediárias aos demais grupos (Tabela 2). As florestas são distintas entre si mas, de modo geral, possuem árvores de porte elevado.

Além da variação nas características do componente arbóreo das florestas, os demais fatores ambientais também variaram diferentemente ao longo do rio Tibagi. A razão entre a largura máxima do rio e a largura máxima da planície varia de 1 (planícies muito estreitas ou inexistentes) a 0,04 (onde a largura máxima da planície alcança valores muito superiores à largura máxima do rio). Esta mesma variação é retratada no perfil longitudinal do rio (Figura 3), onde se observa que há pouca variação em altitude entre as áreas com formação de amplas planícies (trecho das áreas 4 - 12). As maiores variações em altitude foram registradas entre as áreas com planícies muito estreitas ou inexistentes (trecho das áreas 1- 3 e 13 - 23).

Dentre os fatores ambientais empregados na análise de regressão, apenas o diâmetro máximo dos indivíduos arbóreos se mostrou significativamente relacionado com a riqueza de epífitos (Tabela 3).

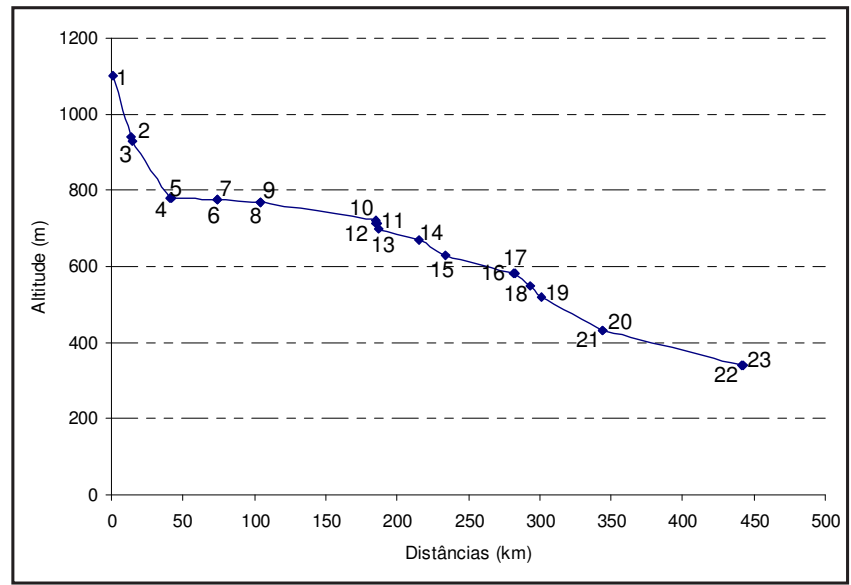

FIGURA 3: Perfil longitudinal do rio Tibagi entre as áreas de estudo, representadas pela numeração de 1-23.

TABELA3: Nível de significância, estimativa e erros dos parâmetros do modelo de regressão obtidos para o efeito do número de espécies de epífitos. Coeficiente de determinação $\left(\mathrm{R}^{2}\right)$ $=0,9697$; erro quadrático médio $(\mathrm{EQM})=$ 0,0237 ; número de observações $(\mathrm{n})=19$.

\begin{tabular}{lccc}
\multicolumn{1}{c}{ Fatores ambientais } & Prob $>$ t & $\begin{array}{c}\text { Estima- } \\
\text { tiva }\end{array}$ & Erro \\
\hline $\begin{array}{l}\text { menor precipitação média } \\
\text { mensal }\end{array}$ & 0,1289 & - & - \\
$\begin{array}{l}\text { menor temperatura média } \\
\text { mensal }\end{array}$ & 0,9493 & - & - \\
$\begin{array}{l}\text { precipitação total } \\
\text { altitude na área de estudo }\end{array}$ & 0,2730 & - & - \\
$\begin{array}{l}\text { razão entre largura rio e a } \\
\text { largura planície }\end{array}$ & 0,7438 & - & - \\
presença ou ausência de & 0,3707 & - & - \\
$\begin{array}{l}\text { cachoeiras } \\
\text { presença ou ausência de solos } \\
\text { hidromórficos }\end{array}$ & 0,5797 & - & - \\
$\begin{array}{l}\text { diâmetro à altura do peito } \\
\text { máximo das árvores }\end{array}$ & 0,0492 & 0,5685 & 0,2454 \\
$\begin{array}{l}\text { altura máxima das árvores } \\
\text { densidade total das árvores } \\
\text { número de espécies de árvores }\end{array}$ & 0,1659 & - & - \\
\hline
\end{tabular}

\section{Discussão}

A riqueza total de epífitos vasculares, registrada ao longo do rio Tibagi, é superior àquela obtida nos demais levantamentos florísticos em ambientes fluviais, inclusive àqueles realizados em áreas mais amplas (Kersten e Kuniyoshi, 2009). Esse elevado 
número de espécies está relacionado, provavelmente, com a extensão de área amostrada (23 áreas de estudo ao longo de, aproximadamente, $500 \mathrm{~km}$ ) e elevada heterogeneidade ambiental existente ao longo do rio Tibagi (Tabela 2).

As famílias com maior número de representantes (Orchidaceae, Polypodiaceae e Bromeliaceae) assemelham-se àquelas registradas como mais importantes em outras regiões do Sul e Sudeste brasileiros (Dittrich et al., 1999; Rogalski e Zanin, 2003; Giongo e Waechter, 2004; Breier, 2005; Kersten e Kuniyoshi, 2009). Este resultado também é considerado comum no âmbito mundial (Kersten e Kuniyoshi, 2009), sendo relacionado com a riqueza destes grupos no ambiente epifítico.

O efeito da elevada heterogeneidade ambiental sobre o componente epifítico também se manifestou no índice de diversidade beta $(\mathrm{Bt}=4,34)$, superior àqueles obtidos em outras regiões, como na planície do rio Iguaçu, PR (Bonnet, 2006; $\mathrm{Bt}=1,12$ ) e na planície costeira do Rio Grande do Sul (Waechter, 1992; Bt = 1,39), ambas com grandes extensões geográficas. Este resultado evidencia a singularidade das comunidades epifíticas e sua importância para conservação dos ecossistemas florestais ao longo do rio Tibagi. Breier (2005) também observou grande substituição de epífitos entre quatro formações florestais do estado de São Paulo, onde apenas uma espécie - Pleopeltis pleopeltifolia (Raddi) Alston foi comum a todas as áreas. Küper et al. (2004) obtiveram resultados semelhantes, constatando substituições florísticas mínimas de $70 \%$ entre áreas separadas por não mais do que alguns quilômetros em ambiente montano do Equador.

As comunidades epifiticas foram mais semelhantes entre áreas de estudo próximas geograficamente, padrão de semelhança já esperado. Os grupos e subgrupos de comunidades distribuídas ao longo do rio (Figura 2) podem ser caracterizados por conjuntos de fatores ambientais.

As comunidades epifíticas reunidas no grupo I, localizadas no alto Tibagi, são distintas entre si. O subgrupo "a" ou segmento da cabeceira (Figura 2a) apresenta a comunidade com maior riqueza epifítica do grupo (área 2 - Tabela 2), resultado diretamente relacionado ao maior diâmetro dos indivíduos arbóreos ali existentes. Grandes forófitos oferecem maior área para fixação das plântulas, maior possibilidade de formação de microclimas diversos, como também devem estar a um período maior de tempo crescendo na floresta (Yeaton e Gladstone, 1982; Hietz e Hietz-Seifert, 1995; Breier, 2005; Flores-Palacios e García-Franco, 2006; Bonnet et al., 2007).

Além da influência positiva dos diâmetros arbóreos na riqueza de epífitos (Tabela 3), deve-se considerar outros fatores ambientais importantes para estas plantas, como a umidade atmosférica (Gentry e Dodson, 1987; Laube e Zotz, 2003). Condições macro e microclimáticas de muita umidade são formadas neste segmento do rio em região de cuesta, formação geomorfológica que pode alcançar $1.200 \mathrm{~m}$ de altitude e separa o primeiro do segundo planalto paranaense. A cuesta, que figura como um grande degrau separando paisagens, atua como obstáculo orográfico, forçando a precipitação da umidade contida nos ventos úmidos provindos do mar e resultando num acréscimo de 100 a $300 \mathrm{~mm}$ de chuva por ano quando comparado ao primeiro planalto (Maack, 2002). Ao longo de todo o ano, mas com maior intensidade no inverno, também se observa a presença de nevoeiro cobrindo a região do altíssimo Tibagi. Neste sentido, a proximidade da cuesta é fonte de intensa umidade para as plantas epifíticas, que não possuem o solo como fonte de água e de nutrientes. Esta relação também foi registrada próximo à segunda cuesta paranaense, onde os epífitos foram mais diversos em áreas com elevadas cotas altimétricas (até $1.250 \mathrm{~m}$ s.n.m.) que, constantemente, apresentam densos nevoeiros (Bonnet et al., 2009). Localmente, a intensa umidade dos cânions, formados nos trechos onde o rio Tibagi apresenta grande perda de altitude em uma curta distância (Figura 3), é fornecida pela aspersão e vaporização da água das corredeiras e cachoeiras. Árvores que se curvam por sobre o canal comumente apresentam maior abundância de plantas epifíticas. Pode-se destacar ainda que, nesses ambientes de conformação muito estreita, a proteção dos ventos e da luminosidade intensa propicia a formação de microclimas específicos para este grupo de plantas, como também destacado em estudo realizado na Serra da Mantiqueira, MG (Menini Neto et al., 2009). 
As comunidades epifíticas que formam o subgrupo "b", localizadas na porção do rio onde o padrão do leito é meandrante livre (Figura 2b), apresentam a menor riqueza epifítica registrada ao longo do rio Tibagi (Tabela 2). Este resultado está relacionado ao baixo diâmetro das árvores que formam as florestas deste trecho (Tabela 2), além de outros condicionantes ambientais não capturados pela análise estatística, mas observados em campo. Nesse segmento do rio há pouca perda de altitude do canal (Figura 3), o que proporciona a formação de extensas planícies e a ocorrência de frequentes inundações que afetam as árvores (Curcio, 2006), mas também afetam os epífitos que ali se instalam. Nestes ambientes, sua fixação e sobrevivência é possível, apenas, em alturas dos forófitos superiores ao nível máximo das inundações, pois são eliminados periodicamente pela água do rio (Bonnet, 2006). Desse modo, sugere-se que não só os ambientes fluviais são distintos em epífitos dos ambientes de encosta (Kersten e Kuniyoshi, 2009), como o padrão de leito do rio influencia na composição das comunidades epifíticas, sendo as florestas que margeiam os trechos de rio com padrão meandrante livre mais pobres em epífitos do que aquelas que margeiam trechos com padrão encaixado.

As comunidades epifíticas reunidas no grupo II, registradas no médio Tibagi, são, na sua grande maioria, muito diversas, o que está positivamente relacionado à presença de grandes árvores nas florestas deste segmento do rio (Tabela 2). Ressaltam-se os fatores ambientais cuja relação com a riqueza de epífitos não foi captura pelas análises, como a ausência de inundações, devido ao soerguimento das margens, além da maior umidade fornecida pelas corredeiras e cachoeiras, geralmente originadas por diques de diabásio que cruzam o canal transversalmente. Outro aspecto é o bom estado de conservação das florestas que sustentam as comunidades reunidas no subgrupo "e", efetivamente mantidas como áreas de preservação permanente e contínuas por grandes extensões. Estas florestas crescem em encosta, muitas vezes bastante íngremes, pois o rio está completamente encaixado. As margens são, por vezes, formadas por grandes depósitos de matacões de diversos tamanhos, onde existe uma série de epífitos facultativos, ou seja, espécies que podem ser observadas crescendo sobre solo/ rochas e, na mesma área, crescendo epidendricamente.
Ou seja, a complexidade estrutural dos hábitats ali existentes provavelmente favorecem a diversificação epifítica neste segmento do rio (Tabela 2). Neste grupo de espécies facultativas pode-se citar as piperáceas, como Peperomia alata Ruiz \& Pav. e Peperomia martiana Miq. e bromeliáceas, como Aechmea distichantha Lem. e Wittrockia cyathiformis (Vell.) Leme. E, finalmente, um último fator ambiental a ser considerado na discussão para as florestas deste trecho do rio é o contato das unidades fitogeográficas, ou seja, a transição entre elas. A vegetação apresenta, concomitantemente, elementos da Floresta Estacional Semidecidual (FES), Floresta Ombrófila Mista (FOM) e Savana, imprimindo ao conjunto fisionomia distinta e de relevante beleza. Nestes ambientes foram observadas espécies como Nidularium procerum Lindm. e Vriesea flava A.F.Costa, H.Luther \& Wand., até então com registro de distribuição restrita ao domínio da Floresta Ombrófila Densa (Reitz, 1983; Costa et al., 2004).

As comunidades reunidas no grupo III, registradas no baixo Tibagi, apresentam riquezas menores, semelhantes àquelas do alto Tibagi. Diferente destas, no entanto, as comunidades do baixo Tibagi apresentam pequena quantidade de indivíduos colonizando as florestas fluviais. Este resultado está, provavelmente, relacionado à menor disponibilidade hídrica que existe em toda a região do baixo Tibagi, comprovadamente desfavorável para as plantas epifíticas. Este padrão foi citado por Borgo et al. (2002), para florestas sob domínio da FES do Paraná. Segundo Kreft et al. (2004), parâmetros climáticos, como a precipitação anual e sua distribuição ao longo do ano, podem ser considerados preditores da diversidade epifítica. Estudos mostram que o crescimento dos epífitos é mais limitado pela água do que por nutrientes (Laube e Zotz, 2003), sendo as plântulas especialmente sensíveis à seca (Zotz e Hietz, 2001). Apesar de a precipitação anual, nesta região, ser próxima a algumas regiões de Floresta Ombrófila Densa no sul do Brasil, a chuva ocorre de modo concentrado ao longo do ano (Tabela 2), com registro de períodos de até 30 dias sem precipitação, além de menor umidade média mensal. Associando temperaturas médias do mês mais quente acima de $27,1^{\circ} \mathrm{C}$ (IAPAR, 2008), é provável que os epífitos desta região sofram mais restrições pelas condicionantes climáticas do que ocorre na região da FOM e no ecótono. 
O número de espécies registrado nas áreas do baixo Tibagi, no entanto, é superior aos obtidos em outros estudos da FED (Borgo et al., 2002, 32 espécies; Dettke et al., 2008, 29 espécies), o que pode estar relacionado, principalmente, com a influência da proximidade do curso de água para as florestas fluviais. Em regiões com menor umidade, como a de Londrina, é provável que a presença do rio seja mais importante na diversificação epifítica local do que em regiões como, por exemplo, próximas ao oceano (FOD), onde a umidade relativa do ar é constantemente mais elevada. Na área de estudo da FES, a contínua evaporação da água, associada à neblina, que comumente se forma sobre o rio nas primeiras horas do dia, são fatores de incremento da umidade do ar, o que favorece desproporcionalmente a diversificação de epífitos em florestas fluviais de regiões com macroclima mais seco.

A partir dos resultados foi possível concluir que é alta a riqueza total de epífitos ao longo do rio Tibagi, sendo variável o número de espécies registradas nas áreas de estudo. As áreas de estudo com maior similaridade florística são aquelas com maior proximidade geográfica, formando-se três grandes grupos de comunidades epifíticas, distribuídas na região do alto, médio e baixo Tibagi.

A substituição de epífitos ao longo do rio é muito elevada, resultando em comunidades epifíticas singulares e de grande importância para conservação dos ecossistemas florestais fluviais estudados. Esta diversidade beta é, provavelmente, resultado da heterogeneidade e complexidade ambiental que se expressa, principalmente, por distintos padrões geomorfológicos e condições climáticas entre as áreas de estudo e entre regiões ambientalmente diferentes do rio.

O diâmetro máximo dos indivíduos arbóreos mostrou-se positivamente relacionado com a riqueza epifítica, indicando sua importância na ampliação da diversidade alfa.

\section{Agradecimentos}

Aos especialistas Americo D. Neto, Cássia Sakuragui, Dalton H. Baptista, Jorge L. Waechter, Marcus A. N. Coelho, Marilia Borgo, Paulo H. L.
Evangelista, Rosângela C. Tardivo, equipe do Museu Botânico Municipal, sem os quais este trabalho não teria sido possível; ao $\mathrm{CNPq}$, pelo apoio financeiro ao projeto e bolsa de estudos; à Klabin S.A., à Embrapa Florestas e ao Iapar, pelo suporte.

\section{Referências}

Araújo, A.C.; Fischer, E.; Sazima, M. 2004. As bromélias na região do rio Verde. In: Marques, O. A. V. \& Duleba, W. (Eds). Estação Ecológica Juréia-Itatins. Ambiente físico, flora e fauna. Holos, Ribeirão Preto, Brasil, p.162-171.

Benzing, D.H. 1995. Vascular epiphytes in Forest Canopies. In: Lowman, M. D. \& Nadkarni, N. M. (Eds.). Forest Canopies. Academic Press, New York, USA. p.225-254.

Bonnet,A. 2006. Caracterização fitossociológica das bromeliáceas epifíticas e suas relações com os fatores geomorfológicos e pedológicos da planície do rio Iguaçu, Paraná, Brasil. Tese de Doutorado, Universidade Federal do Paraná, Brasil, 289pp.

Bonnet, A.; Queiroz, M. H.; Lavoranti, O. J. 2007. Relações de bromélias epifíticas com características dos forófitos em diferentes estádios sucessionais da Floresta Ombrófila Densa. Floresta, 37: 8394.

Bonnet, A. 2009. Epífitos vasculares das florestas do rio Tibagi. Relatório (pós-doutorado). Universidade Federal do Paraná, Brasil, $52 \mathrm{pp}$.

Bonnet, A.; Lavoranti, O. J.; Curcio, G. R. 2009. Epífitos vasculares no Corredor de Biodiversidade Araucária, bacia do rio Iguaçu, Paraná, Brasil. Cadernos de Biodiversidade, 6 (2): 49-70.

Borgo, M.; Silva, S. M.; Petean, M. P. 2002. Epífitos vasculares em um remanescente de Floresta Estacional Semidecidual, município de Fênix, PR, Brasil. Acta Biologica Leopoldensia, 24: 121-130.

Breier, T. B. 2005. O epifitismo vascular em florestas do sudeste do Brasil. Tese de Doutorado, Universidade Estadual de Campinas, Brasil, 139pp.

Costa, A. F.; Luther, H. E.; Wanderley, M. G. L. 2004. A new species of Vriesea (Bromeliaceae) from the Atlantic Forest, Brazil. Novon, 14: 36-39.

Curcio, G. R. 2006. Relações entre geologia, geomorfologia, pedologia e fitossociologia nas planícies fluviais do rio Iguaçu, Paraná, Brasil. Tese de Doutorado, Universidade Federal do Paraná, Brasil, 488pp.

Dettke, G. A.; Orfrini, A. C.; Milaneze-Gutierre, M. A. 2008. Composição florística e distribuição de epífitas vasculares em um remanescente alterado de Floresta Estacional Semidecidual no Paraná, Brasil. Rodriguésia, 59 (4): 859-872.

Dittrich, V. A. O.; Kozera, C.; Silva, S. M. 1999. Levantamento florístico dos epífitos vasculares do Parque do Barigui, Curitiba, Paraná, Brasil. Iheringia Série Botânica, 52: 11-21.

Draper, N. R.; Smith, H. 1981. Applied regression analysis. $3^{\text {rd }}$ ed. John Wiley e Sons, New York, USA, 709pp.

Filgueiras, T. S.; Nogueira, P. E.; Brochado, A.L.; Guala II, G. F. 1994. Caminhamento: um método expedito para levantamentos florísticos qualitativos. Cadernos de Geociências, 12: 39-43. 
Flores-Palacios, A.; García-Franco J. G. 2006. The relationship between tree size and epiphyte species richness: Testing four different hypotheses. Journal of Biogeography, 33: 323-330.

Galvão, F.; Augustin, C. R.; Curcio, G. R.; Domanowski, B. P.; Kozera, C.; Sawczuk, A. T.; Bonnet, A. 2009. Autoecologia de Guadua aff. paraguayana (Poaceae). Pesquisa Florestal Brasiliera, 58: 5-16.

Gentry, A. H.; Dodson, C. H. 1987. Diversity and biogeography of neotropical vascular epiphytes. Annals of the Missouri Botanical Garden, 74: 205-233.

Giongo, C.; Waechter, J. L. 2004. Composição florística e estrutura comunitária de epífitos vasculares em uma floresta de galeria na Depressão Central do Rio Grande do Sul. Revista Brasileira de Botânica, 27: 563-572.

Hietz, P.; Hietz-Seifert, U. 1995. Composition and ecology of vascular epiphyte communities along na altitudinal gradient in central Veracruz, México. Journal of Vegetation Science, 6: 487498.

IAPAR - Instituto Agronômico do Paraná. 2008. Cartas climáticas. Disponível em $<\mathrm{http}$ ://www.iapar.br $>$. Acesso em 13 de dezembro de 2008.

IPNI - International plant names index. 2009. Disponível em $<$ http://www.ipni.org.> Acesso em 15 de fevereiro de 2009.

Kersten, R. A. 2006. Epifitismo vascular na bacia do alto Iguaçu. Tese de Doutorado, Universidade Federal do Paraná, Brasil, 218pp.

Kersten, R. A.; Kunyioshi, Y. S. 2009. Conservação das florestas na bacia do alto Iguaçu, Paraná - Avaliação da comunidade de epífitas vasculares em diferentes estágios serais. Floresta, 39: 51-66.

Kreft, H.; Koster, N.; Küper, W.; Nieder, J.; Barthlott, W. 2004. Diversity and biogeography of vascular epiphytes in Western Amazonia, Yasuni, Ecuador. Journal of Biogeography, 31: $1463-$ 1476.

Küper, W.; Kreft, H.; Nieder, J.; Koster, N.; Barthlott, W. 2004. Large-scale diversity patterns of vascular epiphytes in Neotropical montane rain forests. Journal of Biogeography, 31: 1477-1487.
Laube, S.; Zotz, G. 2003. Which abiotic factors limit vegetative growth in a vascular epiphyte? Functional Ecology, 17: 598-604.

Maack, R. 2002. Geografia física do estado do Paraná. $3^{\mathrm{a}}$ ed. Imprensa Oficial, Curitiba, Brasil, 438pp.

Magurran, A. E. 1988. Ecological diversity and its measurement. Princeton University Press, New Jersey. USA, 179pp.

Menini Neto, L.; Matozinhos, C. N.; Abreu, N. L.; Valente, A. S. M.; Antunes, K.; Souza, F. S.; Viana, P. L.; Salimena, F. R. G. 2009. Flora vascular não-arbórea de uma floresta de grota na Serra da Mantiqueira, Zona da Mata de Minas Gerais, Brasil. Biota Neotropica, 9 (4): 1-13.

Reitz, R. 1983. Bromeliáceas e a malária - Bromélia endêmica. Flora Ilustrada Catarinense, fasc. BROM: 1-559.

Rogalski, J. M.; Zanin, E. M. 2003. Composição florística de epífitos vasculares no estreito de Augusto César, floresta Estacional Decidual do Rio Uruguai, RS, Brasil. Revista Brasileira de Botânica, 26: 551-556.

Silva, S. M.; Britez, R. M.; Souza, W. S.; Motta, J. T. W. 1997. Levantamento florístico em área de várzea do rio Iguaçu, São Mateus do Sul, PR, Brasil. Arquivos de Biologia e Tecnologia, 40: 903-913.

Waechter, J. L. 1992. O epifitismo vascular na planície costeira do Rio Grande do Sul. Tese de Doutorado, Universidade Federal de São Carlos, Brasil, 163pp.

Yeaton, R. I.; Gladstone, D. E. 1982. The pattern of colonization of epiphytes on Calabash Trees (Crescentia alata HBK.) in Guanacaste Province, Costa Rica. Biotropica, 14: 137-140.

Zotz, G.; Hietz, P. 2001. The physiological ecology of vascular epiphytes: current knowledge, open questions. Journal of Experimental Botany, 52: 2067-2078. 